03

\title{
Дискретно-капельный режим обледенения цилиндра в поперечном переохлажденном потоке
}

\author{
(C) А.В. Кашеваров, ${ }^{1}$ А.Л. Стасенко ${ }^{1,2}$ \\ ${ }^{1}$ Центральный аэрогидродинамический институт, \\ 140180 Жуковский, Московская обл., Россия \\ ${ }^{2}$ Московский ффизико-технический институт, \\ 141701 Долгопрудный, Московская обл., Россия \\ e-mail: a.v.kash@yandex.ru
}

Поступило в Редакцию 23 апреля 2019 г.

В окончательной редакции 23 апреля 2019 г.

Принято к публикации 1 июня 2019 г.

Развита физико-математическая модель пространственно-временной эволюции слоя льда, растущего при соударении с поверхностью твердого тела отдельных капель, скользящих вдоль поверхности и отвердевающих на ней, что приводит к двумерной шероховатости (бугристой наледи). На примере поперечно обтекаемого кругового цилиндра приведены иллюстрации результатов расчетов для набора управляющих параметров, характерных для наземных экспериментов в аэрохолодильной установке.

Ключевые слова: большие переохлажденные капли, соударение, рельеф поверхности, метод Монте-Карло.

DOI: $10.21883 /$ JTF.2020.01.48659.173-19

\section{Введение}

Экспериментальные и теоретические исследования обледенения летательного аппарата и элементов конструкции электросиловых и промышленных объектов проводятся в течение почти столетия с учетом большого разнообразия конкретных режимов этого нежелательного явления. Численное моделирование обледенения летательного аппарата проводят на основе сложившихся представлений о физике этого процесса. Давно известно, что он связан, в частности, с отвердеванием переохлажденных капель на поверхности орошаемого тела.

При слабо отрицательных температурах окружающей среды не происходит полного замерзания капли в месте удара. Часть ее массы остается жидкой и, как принято считать, прибывающие капли способны создать движущуюся тонкую пленку. Ее постепенное замерзание приводит к образованию глянцевитой наледи роговидной формы. Движение воды вдоль поверхности учитывается в известных программах для расчета обледенения, таких как LEWICE, TRAJICE или код ONERA [1].

Жидкая пленка может возникнуть также при попадании кристаллов льда на теплые поверхности элементов конструкции летательного аппарата. Режим кристаллического обледенения активно изучается в последнее время. Например, в [2-4] развивается математическая модель пленки. Расчет по этой модели в случае жидкокапельного обледенения с типичной водностью потока $1 \mathrm{~g} / \mathrm{m}^{3}$ дает для толщины пленки вблизи линии растекания величину менее $10 \mu \mathrm{m}$. Возможность непрерывного течения пленки при такой толщине вызывает сомнения.

Действительно, в экспериментах с моделью крыла [5] движение пленки наблюдалось лишь на небольшом на- чальном участке. Далее вода на поверхности находилась в виде неподвижных капель, которые замерзали снизу и пополняли свой объем за счет капель, прибывающих из воздушного потока. Это приводило к сильно шероховатой поверхности образующегося льда. Отмечено, что шероховатость играет важную роль в процессе обледенения, так как увеличивает теплоотдачу и влияет на темп роста наледи. Вывод [5] заключался в необходимости изменения физических моделей, лежащих в основе вычислительных кодов для режима влажного обледенения.

В то же время работа [5] не опровергала физику обледенения при более низких температурах, когда, как считается, капли мгновенно полностью замерзают в месте удара и образуют слой рыхлого льда. Расчет толщины наледи в этом случае обычно проводят на основе вычисленной плотности потока массы, считая ее непрерывной функцией в зоне орошения.

Последние исследования, например [6], показывают, что замерзание умеренно переохлажденной капли (вплоть до $-20^{\circ} \mathrm{C}$ ) представляет собой хотя и быстрый, но все же не мгновенный процесс, по крайней мере, для большой капли. Он сопровождается потерей ее массы при ударе из-за расплескивания. Оставшаяся на поверхности масса воды сначала растекается, а затем стягивается силами поверхностного натяжения и для ее отвердевания требуется миллисекунды. Понятно, что и орошение каплями поверхности происходит не непрерывно, а дискретно по времени и пространству.

Таким образом, из-за сложности проблемы разработка программ для расчета обледенения еще не завершена. В настоящей работе предлагается новая физикоматематическая модель обледенения за счет отдельных 

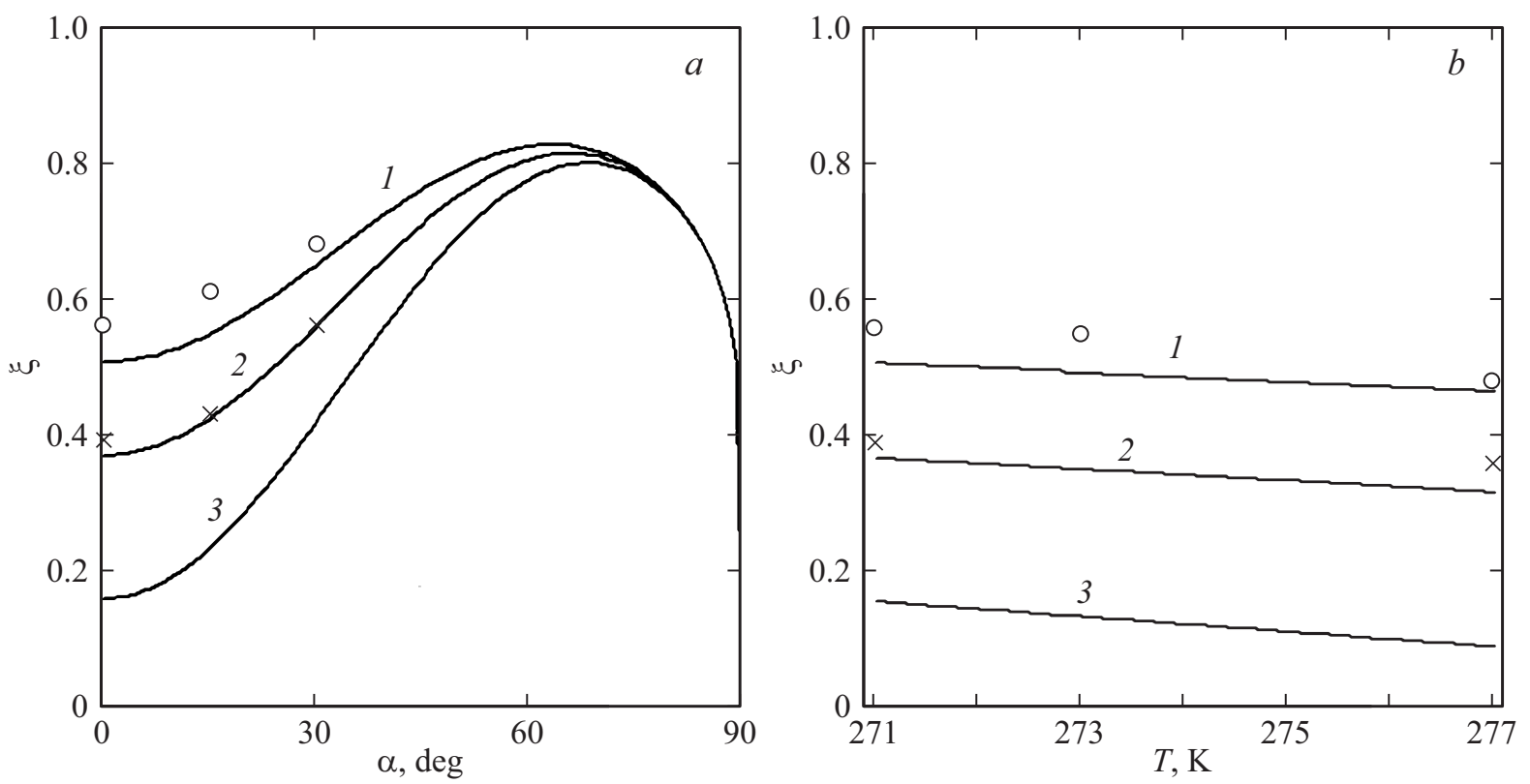

Рис. 1. Зависимости массовой доли воды, оставшейся на поверхности, при ударе капли: $a$ - от угла падения (температура капли $\left.T=-2^{\circ} \mathrm{C}\right) ; b-$ от температуры капли. Точки - экспериментальные данные [7], линии - аппроксимационная зависимость (1). 1 - диаметр падающей капли $d_{0}=235 \mu \mathrm{m}, 2-d_{0}=300 \mu \mathrm{m}, 3-400 \mu \mathrm{m}$.

капель. При формулировании этой модели существенно использованы результаты предшествующих экспериментальных и расчетно-теоретических исследований, позволившие описать последовательность событий, сопровождающих взаимодействие отдельной капли с твердым телом.

\section{1. Экспериментальные и теоретические предпосылки предлагаемой модели}

В [7] экспериментально исследовано взаимодействие капель воды с анодированным алюминиевым стержнем в условиях, близких к летным: скорость потока $u_{\infty}=60-100 \mathrm{~m} / \mathrm{s}$, его температура $T_{\infty}-$ от -20 до $-10^{\circ} \mathrm{C}$. Диаметр капель $d_{0}=235$ или $300 \mu \mathrm{m}$. Температура воды $T$, из которой создавались капли, составляла от -2 до $4^{\circ} \mathrm{C}$.

При соударении крупной капли с твердым телом она расплескивается и лишь часть жидкости остается на поверхности после удара. Доля массы воды, оставшейся на поверхности, от общей массы падающих капель при различных значениях угла падения $\alpha$ и температуры жидкости $T$ представлена в [7] в табличном виде. В расчете на отдельную каплю массой $m_{0}$ эти данные аппроксимированы нами формулой

$$
\begin{aligned}
\xi & =\frac{m}{m_{0}}=\left[1-\left|\frac{R_{s}-R_{l}}{R_{s}+R_{l}}\right|^{3} \frac{d_{0}}{d_{*}}\left(\frac{v_{n}}{v_{*}}\right)^{2 / 3}\left(\frac{\mu_{*}}{\mu_{l}}\right)^{1 / 2} \cos ^{2} \alpha\right] \\
& \times \cos ^{1 / 6} \alpha \geq 0 .
\end{aligned}
$$

Здесь $R_{s, l}=\rho_{s, l} c_{s, l}-$ волновые сопротивления (импедансы) материалов поверхности обтекаемого тела и капли $\left(\rho_{s, l}\right.$ и $c_{s, l}$ - плотности соответствующих материалов и скорость звука в них), $v_{n}$ - нормальная составляющая скорости удара, $\mu_{l}-$ вязкость жидкости. Значения опорных параметров: $d_{*}=250 \mu \mathrm{m}, v_{*}=80 \mathrm{~m} / \mathrm{s}$, $\mu_{*}=1.75 \cdot 10^{-3} \mathrm{~Pa} \cdot \mathrm{s}$.

Аппроксимационная зависимость (1) показана на рис. $1, a$.

Формула (1) отражает априорно очевидные факты: доля остающейся на поверхности массы должна уменьшаться с ростом разности импедансов подложки и жидкости, размера и скорости падения капли и уменьшением ее вязкости. Зависимость от угла падения немонотонна: сначала доля массы $\xi$ растет по мере того как столкновение становится все более скользящим, но при угле $\alpha \rightarrow \pi / 2$ должна стремиться к нулю. Как известно, при скользящих ударах капля воды многократно отскакивает даже от водяной поверхности.

Предложенная аппроксимация опытных данных подсказывает некоторые физические соображения. В частности, кубическая зависимость от разности импедансов в (1) может рассматриваться как влияние трехмерного характера взаимодействия частицы и обтекаемого тела, в которых распространяются неплоские волны. Степенная зависимость $d_{0} v_{n}^{2 / 3}$ пропорциональна кубическому корню из кинетической энергии капли.

На рис. $1, b$ показано влияние температуры жидкости генерируемых капель на $\xi$, которое обусловлено температурной зависимостью ее вязкости. Влияние изменения коэффициента поверхностного натяжения воды не существенно. 

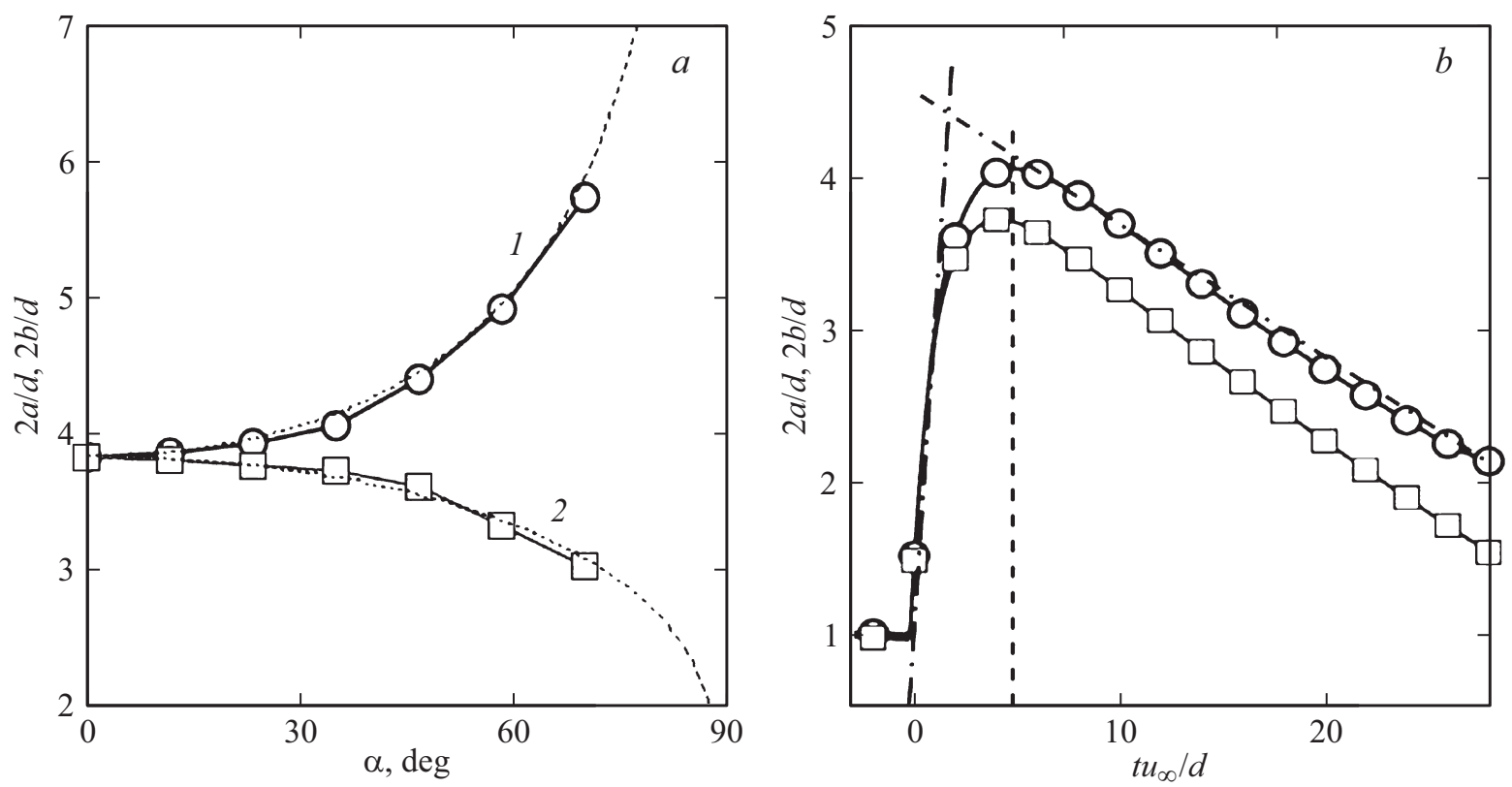

Рис. 2. Результаты численного исследования [8]. $a$ - зависимости обезразмеренных большой 1 и малой 2 осей эллипса контакта столкнувшейся капли $(d=20 \mu \mathrm{m})$ от ее угла падения. Штриховые линии - предлагаемая аппроксимация $(2) ; b-$ эволюция продольного (кружки) и поперечного (квадраты) размера капли после удара о поверхность под углом падения $30^{\circ}$. Штриховая линия разделяет режимы растекания капли и ее стягивания. Штрихпунктирные линии иллюстрируют темп этих процессов.

В [8] численно исследовано трехмерное нестационарное взаимодействие с абсолютно жесткой плоской преградой первоначально сферической капли воды с учетом ее деформации перед столкновением. Для целей настоящей работы использованы результаты [8], полученные для растекания капли по поверхности после столкновения. При наклонном падении форма предельного пятна контакта (в момент прекращения растекания) близка к эллиптической. Большая $a$ и малая $b$ полуоси эллипса могут быть аппроксимированы следующими зависимостями от угла падения (рис. 2, $a$ ):

$$
a=r_{l} \cos ^{-2 / 5} \alpha, \quad b=r_{l} \cos ^{1 / 5} \alpha
$$

где $r_{l}$ - максимальный радиус пятна при нормальном соударении $(\alpha=0)$.

\section{2. Предлагаемая модель}

На основе описанных выше экспериментальных данных и трехмерных расчетов в настоящей работе принят следующий сценарий поведения капли. При ударе часть начальной массы капли разбрызгивается. Оставшаяся доля быстро расплющивается в виде эллиптической лепешки, которая под действием поверхностного натяжения медленно стягивается к центру масс, образуя бугорок. Его основание при этом оказывается уже примерзшей. Для описания формы бугорка принимается аналитическая зависимость, приведенная ниже.

Таким образом, в процессе растекания остатка массы капли по поверхности определяющую роль играют силы вязкости, а в процессе стягивания к центру масс — силы поверхностного натяжения. Разумеется, к этим процессам добавляется еще и кристаллизация, сопровождающаяся первоначальным нагревом воды с последующим отводом тепла в подложку и воздух. Развитие всех этих процессов во времени не описывается, а фиксируются только результаты в конце каждого из них.

Рассмотрим, прежде всего, случай нормального соударения.

Суммарная энергия падающей капли (кинетическая, тепловая, поверхностного натяжения) переходит в энергию брызг, которые в настоящей работе не рассматриваются, и в соответствующие виды энергии остатка капли, распространяющегося по поверхности обтекаемого тела. Как показали оценки, основной диссипативной силой на этой стадии является вязкое трение (вклад поверхностного натяжения составляет $\sim 10 \%$ даже для самых малых капель из рассмотренного диапазона значений $\left.10<d_{0}<1000 \mu \mathrm{m}\right)$. Из соображений размерности работа сил вязкости оценивается соотношением

$$
A_{\mu}=\mu_{l} \frac{v_{n}}{\sqrt{d\left\langle h_{l}\right\rangle}} \pi r_{l}^{2} r_{l} \psi
$$

Здесь $d=\xi^{1 / 3} d_{0}$ - диаметр объемно-эквивалентного шара оставшейся после разбрызгивания массы капли, $\left\langle h_{l}\right\rangle=d^{3} /\left(6 r_{l}^{2}\right)$ - средняя толщина дискообразной лепешки растекшейся массы, $\psi=\sqrt{6}-$ подгоночный множитель, полученный на основе сравнения с [8] (для случая капель с $\left.d_{0}=20 \mu \mathrm{m}\right)$.

Полагая

$$
\xi m_{0} v_{n}^{2} / 2 \sim A_{\mu},
$$



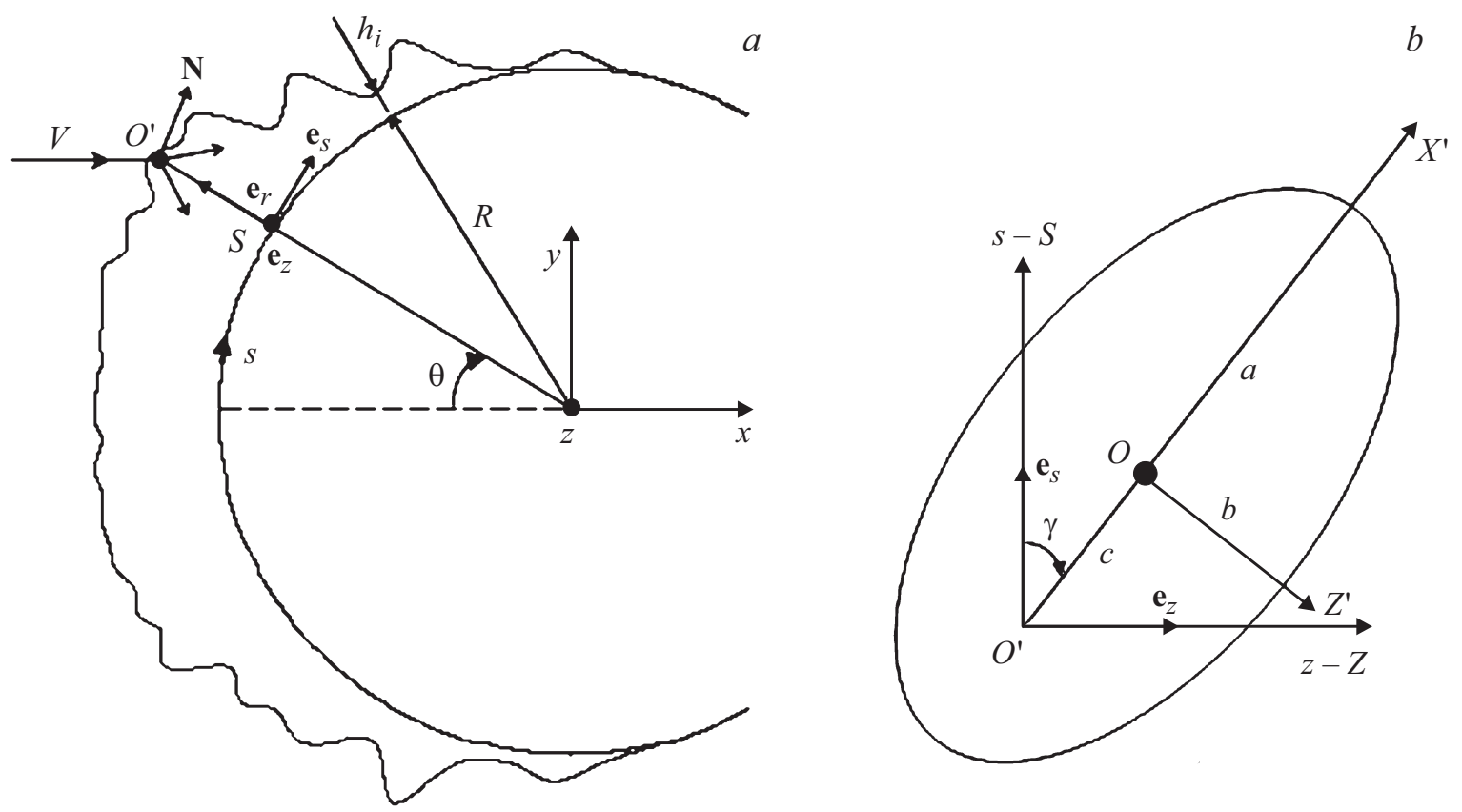

Рис. 3. Системы координат: $a$ - для описания столкновения частицы с поверхностью наледи на цилиндре радиусом $R$ : $N$ - нормаль к поверхности наледи в точке столкновения; $b$ - для описания предельного эллиптического пятна контакта с поверхностью растекшейся капли.

для предельного радиуса диска растекшейся капли получим оценку

$$
r_{l} \sim \frac{\xi^{5 / 12} d_{0}}{\sqrt{12}}\left(\frac{\rho_{l} v_{n} d_{0}}{2 \mu_{l}}\right)^{1 / 4}
$$

Заметим, что здесь пренебрежено еще несколькими видами потерь механической энергии. Например, вследствие большого значения механического эквивалента теплоты не учитывается изменение температуры при деформации капли, растекающейся по поверхности предположение, типичное в рассматриваемом классе задач. Кроме того, пренебрегается превращением части кинетической энергии капли в энергию акустических колебаний. Используя классическую теорию Герца для столкновения двух шаров [9], можно показать, что доля кинетической энергии, теряемой в этом процессе, составляет $\left(v_{n} / c_{w}\right)^{3 / 5} \sim 5 \%$ (при ударе капли со скоростью $50 \mathrm{~m} / \mathrm{s}$ об алюминий).

При наклонном падении, когда $v_{n}=V \cos \alpha(V-$ модуль скорости капли), на бугристую поверхность уже образовавшегося льда, угол падения в точке соударения с координатами $S, R, Z$ (рис. 3,a) определяется из соотношения

$$
\cos \alpha=l_{N} \frac{V_{s}}{V}+m_{N} \frac{V_{r}}{V}+n_{N} \frac{V_{z}}{V} .
$$

Здесь $V_{s}, V_{r}, V_{z}$ - проекции скорости на соответствующие оси прямоугольной системы координат, связанной с необледенелым телом (цилиндром), причем $V_{z}=0$ при обтекании без скольжения, $l_{N}, m_{N}, n_{N}$ - традиционные обозначения направляющих косинусов нормали

$$
\begin{aligned}
& l_{N}=\frac{\partial h_{i}}{\partial s} C, m_{N}=C, n_{N}=\frac{\partial h_{i}}{\partial z} C, \\
& C=\left[\left(\frac{\partial h_{i}}{\partial s}\right)^{2}+\left(\frac{\partial h_{i}}{\partial z}\right)^{2}+1\right]^{-1 / 2},
\end{aligned}
$$

где $h_{i}(s, z)$ - толщина слоя льда.

Так как столкновение происходит на бугристой поверхности, остаток капли соскальзывает под углом $\gamma$ (в системе связанной с цилиндром (рис. $3, b)$ ) относительно плоскости падения:

$$
\operatorname{tg} \gamma=\left(V_{z}-\frac{\partial h_{i}}{\partial z} C V \cos \alpha\right) /\left(V_{s}-\frac{\partial h_{i}}{\partial s} C V \cos \alpha\right),
$$

a поскольку пятно контакта этого остатка с поверхностью представляет собой эллипс, то точка центра масс, куда происходит стягивание жидкости силами поверхностного натяжения, смещена от точки падения на расстояние $c=\sqrt{a^{2}-b^{2}}$.

При этом к рельефу наледи $h_{i}(s, z)$, имевшемуся до удара капли, добавляется высота нового образовавшегося бугорка $\Delta h_{i}(s, z)$, форма которого принимается в виде

$$
\begin{gathered}
\Delta h_{i}=h_{m} \cos ^{2}\left(\frac{\pi}{2} \sqrt{\left(\frac{X^{\prime}}{a}\right)^{2}+\left(\frac{Z^{\prime}}{b}\right)^{2}}\right), \\
X^{\prime}=(s-S) \cos \gamma+(z-Z) \sin \gamma-c, \\
Z^{\prime}=-(s-S) \sin \gamma+(z-Z) \cos \gamma .
\end{gathered}
$$



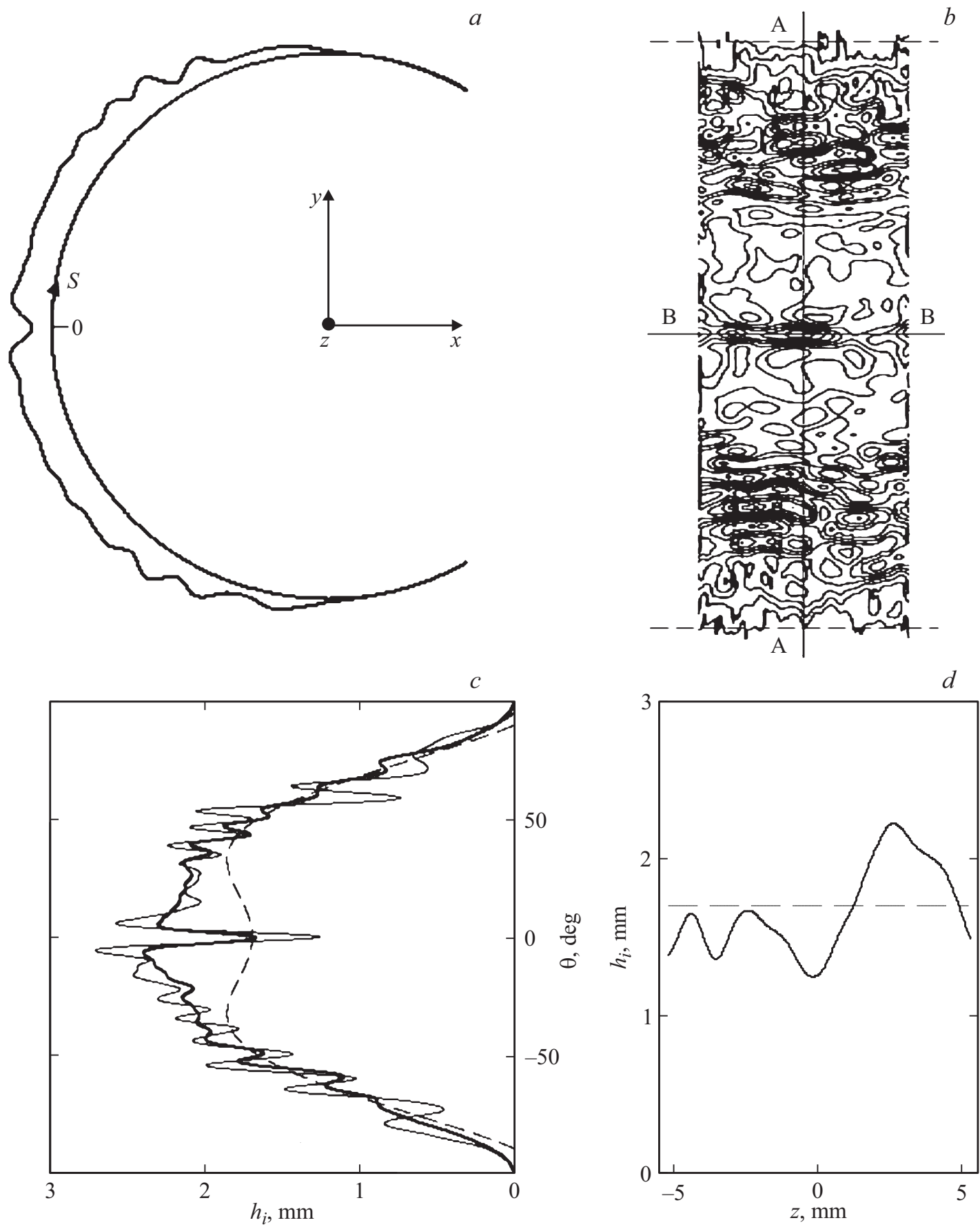

Рис. 4. Результаты расчетов: $a-$ цилиндр с наросшим слоем льда $(t=60 \mathrm{~s})$ в сечении АА; $b-$ линии равной толщины наледи на фронтальной поверхности цилиндра. Штриховые линии - $|\theta|=\pi / 2 ; c-$ угловые зависимости толщины наледи в сечении АА. Сплошные линии - дискретно-капельная модель (жирная - толщина, осредненная по всем сечениям, параллельным АА), штриховая - толщина, найденная по $(6) ; d-$ изменение толщины в сечении ВВ.

Предложенное выражение учитывает условие абсолютной смачиваемости льда водой на границе эллиптического подножия капли. При этом контактный угол равен нулю, в отличие от случая взаимодействия капли воды с поверхностью алюминия [6,7]. Сечения бугорка плоскостями, перпендикулярными ее максимальной высоте $h_{m}$, остаются эллипсами, подобными ее подножью. Значение $h_{m}$ находится из условия сохранения массы $m$ остатка капли:

$$
h_{m}=\frac{1}{3} \frac{\xi d^{3}}{a b} \frac{\pi^{2}}{\pi^{2}-4} \frac{\rho_{l}}{\rho_{i}},
$$

где $\rho_{l}$ - плотность льда.

Разумеется, предложенное выражение (4) не единственно возможное. Эксперименты с крупными теплыми каплями, аккуратно помещенными на холодную поверх- 
ность, например [10], показали, что в конце процесса кристаллизации на вершине капли образуется заострение. Если этот факт имеет отношение и к остатку переохлажденной капли, испытавшей разрушительное столкновение, то можно легко уточнить зависимость (4).

В процессе обледенения изначально свободная ото льда металлическая поверхность покрывается все более толстым слоем наледи. Волновые сопротивления металла $R_{w}$ и льда $R_{i}$ различны. Интуитивно ясно, что с увеличением толщины наледи влияние физикомеханических свойств обтекаемого тела должно становиться все менее значительным. Предположив, что основную роль здесь играет отношение характерных времен прохождения звуковых возмущений в слое льда и остатке капли, примем для импеданса обледеневающей поверхности следующее выражение:

$$
R_{s}=R_{w} e^{-h_{i} \alpha_{i}}+R_{i}\left(1-e^{-h_{i} \alpha_{i}}\right), \alpha_{i}=\left(c_{l} / c_{i}\right) d^{-1},
$$

где $c_{i}$ - скорость звука во льде.

\section{3. Численная реализация. Результаты и обсуждение}

Модель была опробована на примере обледенения алюминиевого цилиндра (радиус $15 \mathrm{~mm}$ ), поперечно обтекаемого воздушным потоком со скоростью $u_{\infty}=50 \mathrm{~m} / \mathrm{s}$. Был принят диаметр капель $d_{0}=400 \mu \mathrm{m}$. При таком соотношении размеров можно считать, что капли движутся прямолинейно со скоростью $V=u_{\infty}$. Их массовая концентрация, так называемый LWC (Liquid Water Content), взята равной $1 \mathrm{~g} / \mathrm{m}^{3}$ - типичное значение в проблеме обледенения. Температура окружающей среды $T_{\infty}=253 \mathrm{~K}$.

Покажем, что модель физически непротиворечива при использованном в настоящей работе наборе параметров. На основе (1), (3) получим для радиуса предельного расплющенного диска $r_{l} \sim 1 \mathrm{~mm}$, а для его средней толщины $\left\langle h_{l}\right\rangle \sim 5 \mu \mathrm{m}$. Расплющивание капли происходит за время

$$
\tau_{\text {spread }} \sim r_{l} /\left(v_{n} / 2\right) \sim 4 \cdot 10^{-5} \mathrm{~s} .
$$

Согласно [8] (рис. 2,b), время стягивания расплющенной капли силами поверхностного натяжения $\tau_{\text {back }} \sim 10 \tau_{\text {spread }}$, следовательно, $\tau_{\text {back }} \sim 4 \cdot 10^{-4} \mathrm{~s}$.

Оценим время замерзания капли. На первом этапе переохлажденная капля нагревается до температуры фазового перехода $T_{f}$. Время прогрева диска

$$
\tau_{l} \sim\left\langle h_{l}\right\rangle^{2} / \chi_{l} \sim 2 \cdot 10^{-4} \mathrm{~s},
$$

где $\chi_{l}=1.3 \cdot 10^{-7} \mathrm{~m}^{2} / \mathrm{s}-$ коэффициент температуропроводности воды.

На втором этапе происходит непосредственно замерзание за счет отвода теплоты кристаллизации. Время ее отвода $\tau_{L}$ внутрь слоя образующегося льда (теплоотводом в воздух и разностью энтальпий $c_{p}\left(T_{f}-T_{\infty}\right)$ пренебрегается) можно оценить из решения задачи Стефана [11], согласно которому плотность потока тепла

$$
q=\frac{\lambda_{i}\left(T_{f}-T_{\infty}\right)}{\sqrt{\chi_{i} / \pi}} \sqrt{t}, \int_{0}^{\tau_{L}} q d t=L \rho_{l}\left\langle h_{l}\right\rangle .
$$

Здесь $\lambda_{i}=2 \mathrm{~W} /(\mathrm{m} \cdot \mathrm{K})$ и $\chi_{i}=10^{-6} \mathrm{~m}^{2} / \mathrm{s}$ - коэффициенты теплопроводности и температуропроводности льда, $L=0.33 \mathrm{MJ} / \mathrm{kg}$ - удельная теплота кристаллизации. Температура поверхности тела принята равной $T_{\infty}$.

Из (5) получим

$$
\sqrt{\tau_{L}} \sim \frac{L \rho_{l}\left\langle h_{l}\right\rangle}{\lambda_{i}\left(T_{f}-T_{\infty}\right)} \sqrt{\frac{\chi_{i}}{\pi}}
$$

так что $\tau_{L} \sim 5 \cdot 10^{-4} \mathrm{~s}$.

Заметим, что использованные здесь табличные значения коэффициентов переноса, возможно, не совсем верны для описания высокоскоростного соударения капли с телом, при котором их значения могут вырасти, например, вследствие образования нанокластеров в объеме переохлажденной капли. Этот вопрос требует дополнительного исследования.

Таким образом, показано, что жидкость остатка капли действительно может перемещаться по поверхности, прежде чем замерзнуть. Это проскальзывание представляется незначительным при обтекании крупномасштабных элементов конструкции летательного аппарата, что оправдывает часто принимаемую концепцию мгновенного замораживания, но может быть существенным для более мелких (лопатки двигателя, модели профиля крыла в наземном аэрофизическом эксперименте).

С другой стороны, время заполнения орошаемой площади тела одним слоем капель

$$
\tau_{m}=\frac{\left\langle h_{l}\right\rangle}{v_{n}} \frac{\rho_{l}}{\mathrm{LWC}} \sim 0.1 \mathrm{~s}
$$

оказывается больше, чем время отвердевания капли, т.е. в среднем капли успевают отвердеть на поверхности до приближения капель следующего слоя.

Задача обледенения цилиндра решена методом Монте-Карло. При принятых значениях LWC и $d_{0}$ на одну каплю в среднем приходится кубический объем с ребром куба

$$
\Delta=d_{0} \sqrt[3]{\frac{\pi l}{6 \cdot \mathrm{LWC}}} \approx 32 \mathrm{~mm},
$$

превышающим диаметр обтекаемого цилиндра.

Координаты капли внутри этой кубической ячейки по $y$ и $z$ задавались случайными величинами с равномерными плотностями распределения. Изменение этих двух случайных величин соответствовало времени пролета капли через ячейку $\tau_{V}=\Delta / V \approx 0.00064 \mathrm{~s}$.

Так как капли летят прямолинейно, легко найти координаты их удара о поверхность тела. С помощью формул разд. 2 вычислялась толщина образующейся 
наледи. Для зависимости коэффициента вязкости воды от температуры использовано выражение

$$
\mu_{l}=2.2 \cdot 10^{-9} T \exp (2180 / T) \mathrm{Pa} \cdot \mathrm{s},
$$

причем предельный радиус диска растекшейся капли $r_{l}$, зависящий от $\mu_{l}$, находится по формуле (3) при $T=273 \mathrm{~K}$.

На рис. 4 дана иллюстрация полученных результатов. Показаны профиль бугристости (рис. 4,a) в одном из сечений плоскостью, перпендикулярной оси цилиндра, а также соответствующий развернутый участок поверхности при виде спереди (рис. 4, $b$ ). На рис. 4, $c, d$ представлены изменения толщины наледи как по окружности цилиндра, так и вдоль линии растекания $\theta=0$. Хорошо виден стохастический характер бугристой наледи.

Штриховая кривая рис. 4, с соответствует описанию темпа роста слоя льда, согласно выражению

$$
\rho_{i} d h_{i} / d t=\xi \cdot \mathrm{LWC} \cdot V \cos \alpha
$$

и гипотезе мгновенного примерзания.

Эта кривая одинакова для всех сечений, параллельных АА, в то время как дискретно-капельная модель дает различную картину в этих сечениях. Жирной сплошной кривой на рис. 4, $c$ показан профиль толщины наледи, полученный осреднением 401 профиля в пределах ширины расчетной области (рис. 4,c). Видно, что дискретно-капельная модель предсказывает бо́льшее отложение льда по сравнению с моделью мгновенного примерзания. Это связано с ростом бугров на поверхности, что изменяет средний угол падения капель и увеличивает плотность потока массы за счет коэффициента $\xi$. Однако толщина при $\theta=0^{\circ}$ оказалась одинаковой для обеих моделей. Принятый в настоящей работе учет проскальзывания капель вдоль локальных склонов бугристости приводит к перераспределению накопленной массы и, в частности, к затеканию массы отвердевающей капли на подветренную сторону цилиндра $|\theta|>\pi / 2$.

\section{Заключение}

Предложена альтернатива часто используемой концепции мгновенного примерзания капли при еe высокоскоростном соударении с поверхностью твердого тела. Развитая физико-математическая модель описывает несколько стадий процесса на основе результатов, полученных ранее теоретически и экспериментально. При этом рост наледи выглядит как физически реальный результат суммирования большого числа распределенных во времени и пространстве событий и не требует использования дифференциальных уравнений. Разработанный численный алгоритм позволяет определить стохастические характеристики рельефа бугристой наледи, влияющей на структуру пограничного слоя, в частности, переход ламинарного течения в турбулентное.

\section{Финансирование работы}

Работа выполнена в рамках проекта MUSIC-haic программы HORIZON 2020 ЕC при финансовой поддержке Министерства науки и высшего образования РФ в рамках федеральной целевой программы „Исследования и разработки по приоритетным направлениям развития научно-технологического комплекса России на 2014-2020 годы“, уникальный идентификатор проекта RFMEFI62818X0010.

\section{Конфликт интересов}

Авторы заявляют, что у них нет конфликта интересов.

\section{Список литературы}

[1] Wright W.B., Gent R.W., Guffond D. // NASA Contractor Report 202349. 1997. 52 p.

[2] Камеваров А.В., Стасенко А.Л. // ПМТФ. 2017. T. 58. № 2. C. 103-114. DOI: 10.15372/PMTF20170211 [Kashevarov A.V., Stasenko A.L. // J. Appl. Mechan. Tech. Phys. 2017. Vol. 58. N 2. P. 275-284. DOI: $10.1134 / \mathrm{S} 0021894417020110]$

[3] Камеваров А.В., Левченко В.С., Миллер А.Б., Потапов Ю.Ф., Стасенко А.Л. // ЖТФ. 2018. Т. 88. Вып. 6. C. 808-814. DOI: 10.21883/JTF.2018.06.46009.2503 [Kashevarov A.V., Levchenko V.S., Miller A.B., Potapov Yu.F., Stasenko A.L. // Tech. Phys. 2018. Vol. 63. N 6. P. 782-788. DOI: $10.1134 / \mathrm{S} 1063784218060142]$

[4] Камеваров А.В., Стасенко А.Л. // Теплофизика и аэромеханика. 2019. T. 26. № 2. C. 237-245. [Kashevarov A.V., Stasenko A.L. // Thermophysics and Aeromechanics. 2019. Vol. 26. N 2. P. 237-244. DOI: 10.1134/S0869864319020069]

[5] Olsen W., Walker E. // NASA Tech. Memorandum. 1986. Vol. 87184. 46 p.

[6] Zhang C., Liu H. // Phys. Fluids. 2018. Vol. 8. 062107. DOI: $10.1063 / 1.4953411$

[7] Berthoumieu P. // 4th AIAA Atmospheric and Space Environments Conf., 2012. AIAA 2012-3130. 14 p. DOI: $10.2514 / 6.2012-3130$

[8] Cimpeanu R., Papageorgiou D.T. // Intern. J. Multiphase Flow. 2018. Vol. 107. P. 192-207. DOI: 10.1016/j.jimultiphaseflow.2018.06.011

[9] Каганов М.М. Физика глазами физика. Ч. 1. М. Изд-во МЦНМО, 2014. $176 \mathrm{c}$.

[10] Алексеенко C.B., Mendig C., Schulz M., Sinapius M., Приходько А.А. // Письма в ЖТФ. 2016. Т. 42. Вып. 10. C. 54-61. [Alekseenko S.V., Mendig C., Schulz M., Sinapius M., Pryhodko A.A. // Tech. Phys. Lett. 2016. Vol. 42. N 5. P. 524-527. DOI: 10.1134/S1063785016050187]

[11] Лыков А.В. Теория теплопроводности. Л.: Высшая школа, $1967.600 \mathrm{c}$. 